\title{
Inadequate Management of Multiple Orbital Fractures and Traumatic Optic Neuropathy
}

\author{
Yunia Irawati, Dyah Tjintya, Hernawita Suharko, Syntia Nusanti \\ Department of Ophthalmology, Faculty of Medicine, Universitas Indonesia, Cipto Mangunkusumo Hospital, Jakarta, Indonesia.
}

\begin{abstract}
Corresponding Author:
Dr. Yunia Irawati

Email: yunia_irawati@yahoo.com

This is an Open Access article distributed under the terms of the Creative Commons Attribution License (creativecommons.org/ licenses/by/3.0).
\end{abstract}

Received : April 20, 2017

Accepted : June 19, 2017

Published : July 15, 2017

\begin{abstract}
Background: The purpose of this case report is to demonstrate a re-surgery in patient with inadequate management of multiple orbital fractures and traumatic optic neuropathy as a way to relieve his visual problem. Case Report: A 25 year old male presented with double vision following surgical repair of orbital rim fracture. Right eye examination revealed restricted eye movement in all directions and visual acuity was 2/60. Improvement was noted in diplopia and visual acuity following surgery in our hospital to release tissue entrapment with silicone block implant. Conclusion: Management of multiple orbital fractures should be done simultaneously with multidisciplinary teams for adequate and appropriate management.
\end{abstract}

Keywords: Diplopia, Orbit, Orbital Fractures, Silicones, Visual Acuity.

\section{Introduction}

Multiple orbital fracture is defined as fracture involving more than one bone of orbital cavity $[1,2]$. Orbital fractures are caused by blunt trauma and may result from motor vehicle accidents, sport injuries, industrial accidents, falls, fighting, assault with a blunt object, explosion and rarely orbital or endonasal surgeries $[3,4]$. Incidence of orbital fracture accounts for roughly $10-25 \%$ of all cases of facial fractures [3]. Incidence is higher in third decade of life with male predominance and orbital floor is commonest bone involved [5]. Clinical presentations, complications and management have been described by several authors [3-8].

The goal of surgical repair is to prevent loss of vision, persistent diplopia, and globe malpositioning by removal of all displaced tissue from the fracture site and restoration of orbit architecture. It can be performed immediately after the accident or after two weeks to allow swelling and hemorrhage to subside [6-8]. Multidisciplinary management of multiple orbital fractures should be done to obtain better results and prevent complications.

\section{Case Report}

A 25 years old male presented to us with double vision. Four days before, the patient had an accident while he was riding a motorcycle. He was wearing half-face helmet. His head, face and right eye hit the sidewalk after he fell down from the motorcycle. This was associated with nose bleeding and headache but no history of seizure, unconsciousness, otorrhea, nausea and vomiting. $\mathrm{He}$ received anti-tetanus serum/ tetanus toxoid injection, antibiotics, stitch over the wound on his right upper eyelid around the eyebrow and underwent Computed Tomography (CT) scan in previous hospital. His brain CT scan revealed epidural hematoma and emergency craniotomy was performed immediately. Patient also received methylprednisolone $4 \times 250 \mathrm{mg}$ injection, ranitidine 2x150 mg orally, vitamin D3 and folic acid tablet orally from neuro-ophthalmology division. 
Ophthalmological examination of the right eye [Fig.1] showed restriction of eye movements and diplopia in all directions, visual acuity of $2 / 60$ and low intraocular pressure. Right palpebral examination revealed enophthalmus [Fig.2], hematoma, spasm, edema, ptosis, and orbital rim discontinuity (superior, inferior and lateral) without crepitations. There were sub-conjunctival bleeding at all quadrants [Fig.3]; cornea was clear; camera oculi anterior was deep, no cell and flare; iris and pupil was round, central, dilated on sulfas atropine, light reflex and relative afferent pupillary defect (RAPD) could not be evaluated; lens and vitreous were clear. Fundus examination showed the papil was round, pale, cup disc ratio was hard to be evaluated, artery/vein ratio $2 / 3$, macular reflex was positive, retina was good and no commutio retina. Ophthalmological examination of the left eye was within normal limit (consensual reflex of the left eye was positive) except there was palpebral hematoma. There was no hypesthesia in both eyes.

Orbital CT scan [Fig.4] revealed comminuted fracture of right frontal bone, right anterior wall frontal sinus, right sphenoid wing, right anterior and lateral wall maxilla sinus, and inferior orbital rim; fracture of right posterior and medial maxilla sinus, right zygoma, and left anterior wall maxilla sinus; panhematosinus, right retrobulbar hematoma especially on medial side, reduced epidural hematoma, subdural fluid collection, edema of soft tissue with subcutaneous emphysema. He was diagnosed with diplopia caused by multiple orbital wall fracture of the right eye (right superior, inferior and lateral orbital rim fracture), right palpebral hematoma and subconjunctival bleeding of the right eye, brow ptosis, traumatic optic neuropathy (TON) of the right eye post-craniotomy due to right frontal epidural hematoma.

Patient refused for further treatment in our hospital and underwent surgery in other hospital. But one week following surgery he presented again with diplopia. Ophthalmological examination of

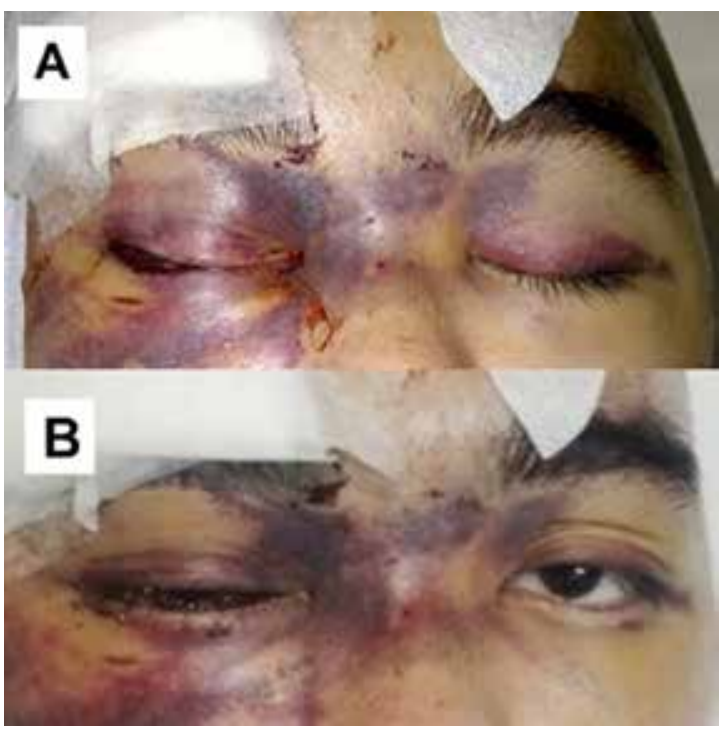

Fig.1: Frontal view four days after accident (A): close eyes (B): open eyes.

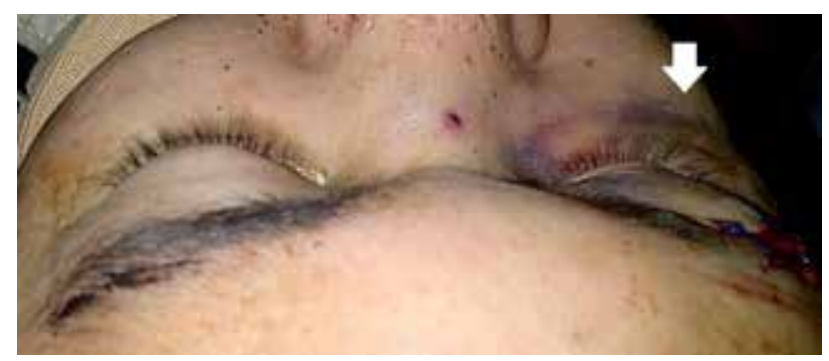

Fig.2: Upper view four days after accident showing enophthalmus of the right eye (arrow).

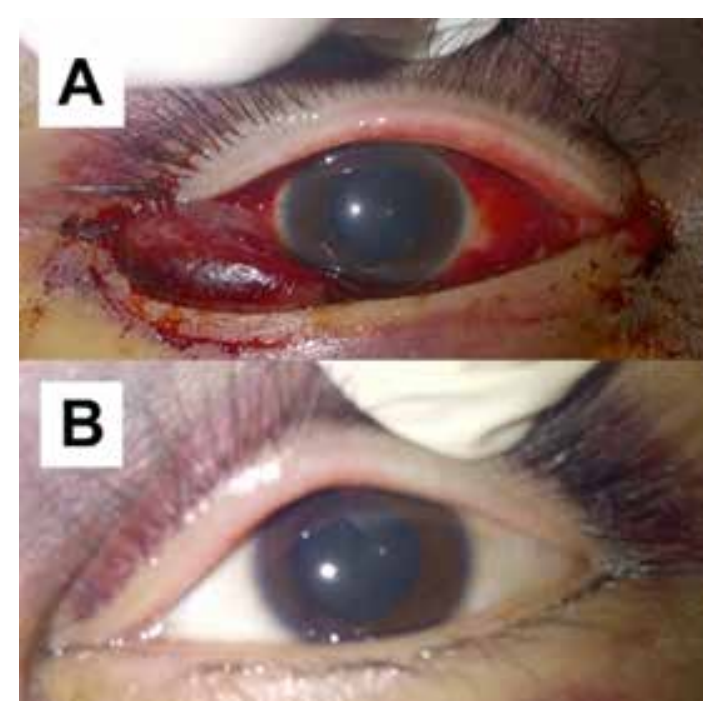

Fig.3: Intraocular condition four days after accident (A): right eye (B): left eye. 
the right eye showed visual acuity $2 / 60$, restriction of eye movements in all directions, the mid-dilated pupil with decreasing light reflex, relative afferent pupillary defect (RAPD) was hard to be evaluated. Ophthalmological examination of the left eye was within normal limit.

Patient was diagnosed with postcraniotomy right superior, inferior and lateral orbital rim fracture with plate and screw, due to right frontal epidural hematoma, diplopia caused by soft tissue entrapment still remained (orbital floor fracture), brow ptosis caused by facial nerve paralysis, and TON of the right eye. We performed the second surgery 45 days after the accident in order to release the soft tissue entrapment and repair orbital fracture with silicone block implant of the right eye [Fig.5].

Two months after his second surgery of orbital fracture, his complaint of double vision was only restricted to superior side maximally. Ophthalmological status of the right eye [Fig.6] revealed visual acuity 6/15 (cum correction), orthophoria, eye movement were present in all directions [Fig.7]; diplopia only to superior side maximally [Fig.8]; intraocular pressure was 10.5 $\mathrm{mmHg}$, palpebral ptosis, lagophthalmus one $\mathrm{mm}$ without corneal exposure, positive enopthalmus, discontinuity and crepitation were negative; conjunctival bulbi was chemotic at inferior side, cornea was clear, camera oculi anterior were deep and no cell and flare; iris/ pupil were mid-dilated and reduced light reflex; lens and vitreus were clear, funduscopy: papil was round, pale, cup disc ratio was hard to be evaluated, artery/venous ratio $2 / 3$, macular reflex was positive, and retina was healthy.

Patient was diagnosed with postreconstruction of multiple orbital fractures with silicone block implant due to blow out fracture and orbital rim fracture with plate and screw of the right eye, post-craniotomy due to right frontal epidural hematoma, TON of the right eye, traumatic brow ptosis. Patient was discharged on artificial tears, methyl-cobalamin with three monthly follow-up.

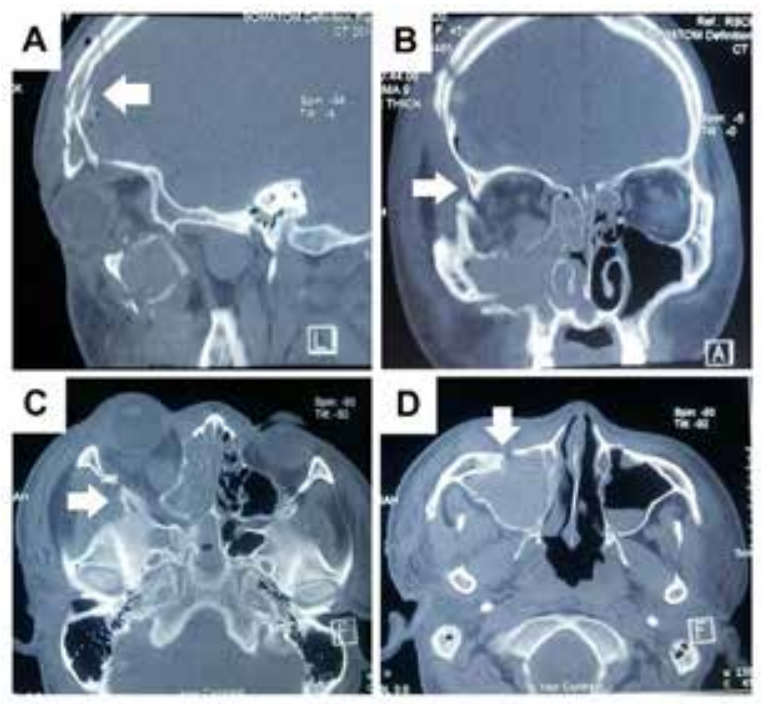

Fig.4: CT scan showing multiple orbital fractures (arrow) (A): sagital view (B): coronal view (C) \& (D): axial view.
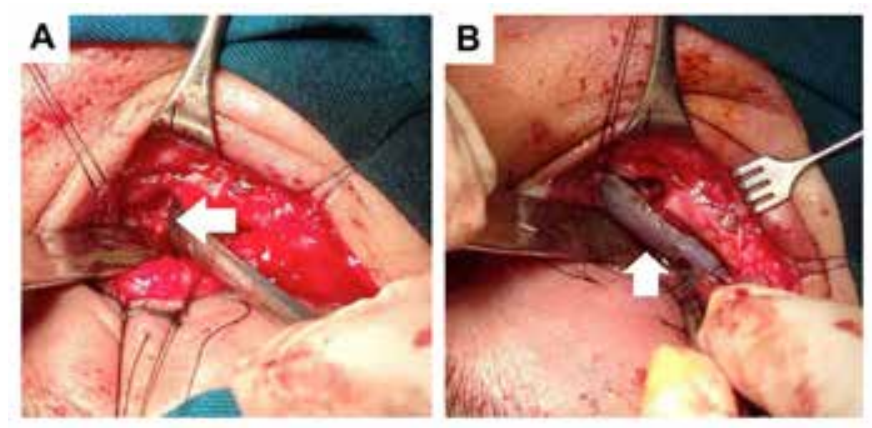

Fig.5: Intraoperative picture (arrow) (A): tissue entrapment (B): silicone block implant.

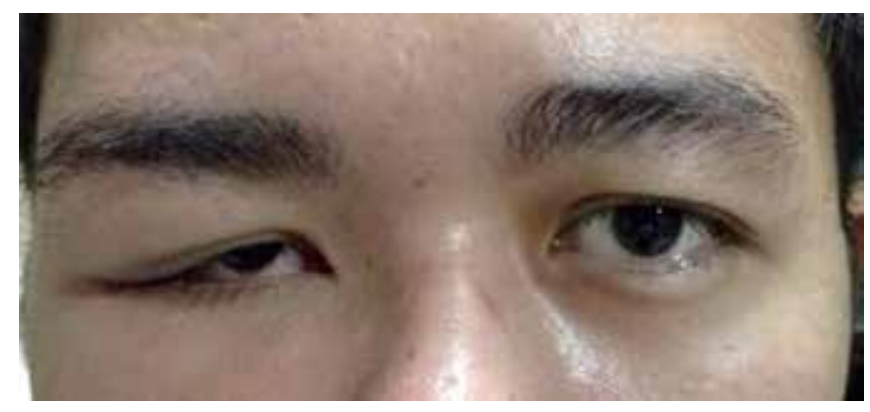

Fig.6: Frontal view two months after second surgery.

\section{Discussion}

Visual disturbance in multiple orbital fractures occurred due to TON or the presence of ocular injuries. Enophthalmos is often seen in orbital floor fracture and medial orbital wall fracture, cause of 


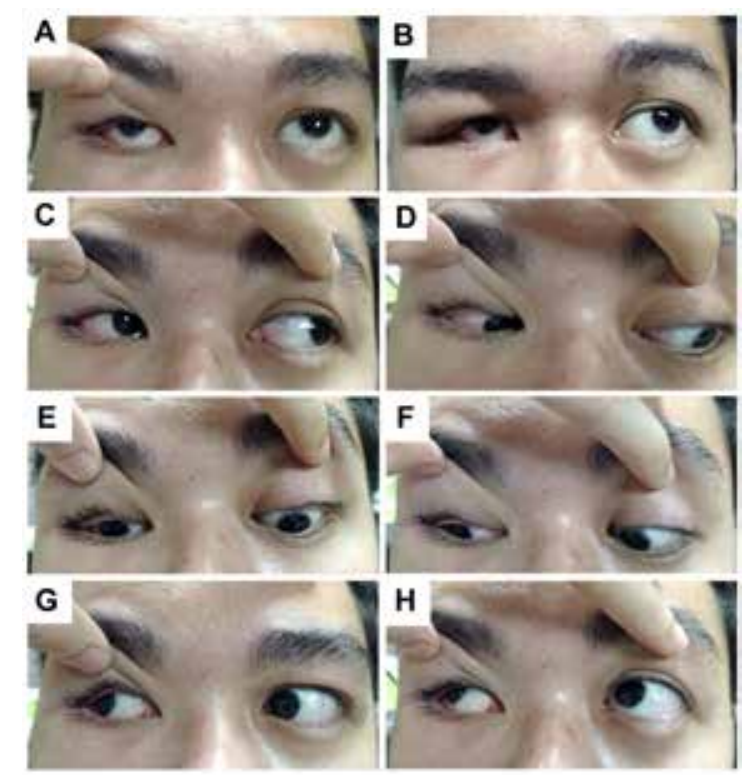

Fig.7: Ocular motilities two months after second surgery (A): upgaze (B): upper left gaze (C): lateral left gaze (D): lower left gaze (E): downgaze (F): lower right gaze (G): lateral right gaze $\mathbf{( H ) : ~ u p p e r ~ r i g h t ~ g a z e . ~}$

enlargement of orbital container. Enophthalmos could be present immediately after trauma or appear later after the reduction of the orbital hemorrhage and edema $[8,10]$. The amount of enophthalmos is usually assessed with Hertel exophthalmometry. CT scans may predict the risk of late enophthalmos according to the extent of the fracture [9]. Restricted eye movement and diplopia to all directions are associated with extraocular muscle entrapment and orbital tissue entrapment that could lead to a compartment-like syndrome resulting tissue ischemia and fibrosis, orbital hemorrhage, edema, or contusion of the orbital structures [10]. Traumatic ptosis associated with orbital fracture may be caused by direct or indirect injuries to the levator palpebrae superior muscle or to its aponeurosis. Orbital and neurosurgical procedures may also lead to traumatic ptosis $[8,11]$.

The primary indications for surgical repair of orbital floor and medial wall fracture are diplopia with limitation of upgaze/downgaze within 300 of the primary position with a positive forced duction test result 7-10 days after injury and

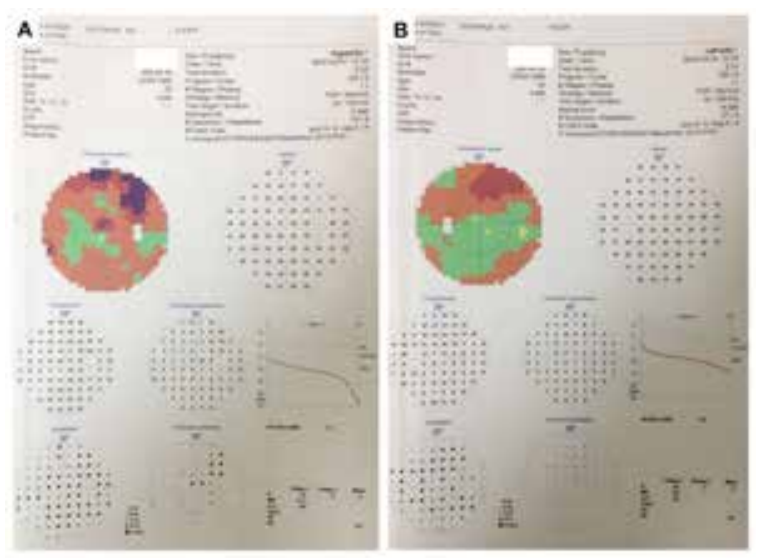

Fig.8: Octopus examination two months after second surgery (A): right eye (B): left eye.

with radiologic confirmation of a fracture of the orbital floor and enophthalmos that exceed $2 \mathrm{~mm}$ and is cosmetically unacceptable to the patient, and large fracture involving at least half of the orbital floor, particularly when associated with large medial wall fracture (determined by CT scan). The indications of other type of orbital fractures mostly are the same. Ptosis, lid retraction, lateral canthal dystopia, flattening of the malar eminence, and trismus, gaze restriction, lagophthalmus, proptosis, exophthalmos are other indications for surgical repair in zygomatico-maxillary fractures and orbital roof fractures. The only urgent indication for surgical repair in all type of orbital fracture is entrapment that causes an oculo-cardiac reflex with bradycardia and cardiovascular instability [3-7].

Blow out fracture in adult should be repaired in 10-14 days. If we perform the repair of orbital fracture before two weeks, risk of hemorrhage is high [6,7]. However if we perform it after one month, the entrapment tissues will be difficult to release due to cicatrix $[8,12,13]$. If there is restriction of eye movement and no subjective improvement as the swelling resolves, surgery is indicated. But if the diplopia is improving and the restriction is minimal, it is better to wait to see if the diplopia continues to resolve. Surgery may not be required. Diplopia in primary position or in downgaze is strong indication to perform surgical 
intervention. Swelling and ecchymosis may mask any asymmetry. If the eye movements are full, wait 2-3 weeks to see if the asymmetry is present. If it exists and the patient is bothered by it, repair is reasonable. But if there's no asymmetry, recheck in a few months [13].

This patient did not show any occulo-cardiac reflex so the surgical repair was not performed immediately. At least 14 days waiting period should be allowed to let the swelling and hemorrhage to subside and to lead the surgical intervention easier to perform and the intervention will not create much hemorrhage. This patient underwent surgical repair of multiple orbital fracture twice. The surgical report showed his previous surgery performed fixation of displaced bones with plate and screw without releasing the entrapped muscle. Therefore, his complaint of diplopia and restriction of eye movements still existed. We released the entrapped muscle and put silicone block implant to prevent tissue entrapment. The operation was performed 45 days after the accident, it was difficult to release all the entrapped tissue due to cicatrix. In the end, most of the entrapped tissue has been successfully released. Two months after the second surgery, his complaint of double vision was minimal, only to superior side maximally and his eye movements were present in all directions.

This patient still has problem of brow ptosis and diplopia to superior side maximally. Brow ptosis in this patient happened due to frontal bone fracture and orbital roof fracture. We plan to observe the ptosis for next six months. After that period, we could decide whether this patient needs surgical intervention or not $[8,13,14]$. Diplopia to superior side maximally occurred because we could not release the entrapped tissue maximally until posterior side and there's cicatrix in the entrapped tissue. We have to observe his remained diplopia until next six months. If there's still diplopia to superior side maximally and interfered his daily life, we have to consult to strabismus division to repair the muscle.
Direct TON arises from penetrating trauma whereas indirect TON occur when the force of impact is imparted into the skull and transmitted to the optic nerve without penetration [15-17]. Despite of ocular manifestations, we have to perform CT scans examination as diagnostic procedure of choice TON to show if there is a bone fracture $[15,17]$. The three commonly recommended approaches for indirect TON are corticosteroid mega-doses, decompression of the optic canal and observation [15-20]. However, one should consider that patient should be informed of this unproven benefit and if there's no response, optic canal decompression through trans-ethmoidal route might be considered. Two months after his second surgery and one month of high dose methyl-prednisolone, his visual acuity improved to $6 / 15$ but the posterior segment was still in the same condition. This patient could not reach the best visual acuity $6 / 6$ due to axonal damage leading to axonal cell death secondary to orbital roof fracture causing edema and focal blockade of axonal conduction.

\section{Conclusion}

The management of multiple orbital fractures should be done with multidisciplinary teams to provide patient adequate and appropriate management. We also have to observe the diplopia to superior side maximally until six months. If there's still diplopia and interfered patient's daily life, we should plan strabismus surgery. This patient still has a problem of brow ptosis and we will observe it until six months.

Contributors: IY: manuscript writing, literature search and case management; DT, HS, SN: manuscript editing, literature search, and case management. IY will act as guarantor. All authors approved the final version of the manuscript.

Funding: None; Competing interests: None stated.

\section{References}

1. American Academy of Ophthalmology Staff. Orbital anatomy. In: American Academy of Ophthalmology Staff, editor. Orbit, Eyelids, and Lacrimal System. San Francisco: American Academy of Ophthalmology; 2007-2008. pp. 5-8. 
2. Joseph JM, Glavas IP. Orbital fractures: a review. Clin Ophthalmol. 2011;5:95-100.

3. Roth FS, Koshy JC, Goldberg JS, Soparkar CN. Pearls of orbital trauma management. Semin Plast Surg. 2010;24:398-410.

4. Alsuhaibani AH. Orbital fracture: significance of lateral wall. Saudi J Ophthalmol. 2010;24:49-55.

5. Hwang K, You SH, Sohn IA. Analysis of orbital bone fractures: a 12 years study of 391 patients. J Craniofac Surg. 2009;20:1218-1223.

6. Burnstine MA. Clinical recommendations for repair of isolated orbital floor fractures. Ophthalmology. 2002;109:1207-1213.

7. American Academy of Ophthalmology Staff. Orbital trauma. In: American Academy of Ophthalmology Staff, editor. Orbit, Eyelids, and Lacrimal System. San Francisco: American Academy of Ophthalmology; 2007-2008. pp. 95-104.

8. Chang A, Carter KD, Nerrad JA. Orbital floor fracture. In: Ng JD Holck DE, editor. Evaluation and Treatment of Orbital Fractures: A multidisciplinary Approach. Philadelphia: Elsevier Saunders; 2006. pp. 93-102.

9. Hamedani M, Pournaras JC, Goldblum D. Diagnosis and management of enophthalmus. Surv Ophthalmol. 2007;52:457-463.

10. Kahana A, Lucarelli MJ, Burkat CN, Dortzbach RK. Orbital fractures. In: Mallajosyula $\mathrm{S}$, editor. Surgical Atlas of Orbital disease. New York: McGrawHill; 2009. pp. 220-241.

11. Edmonson BC, Wulc AE. Ptosis evaluation and management. Otolarnygol Clin N Am. 2005;38:921-946.

12. Sowka JW, Gurwood AS, Kabat AG. Eyelid and adnexa.
In: Sowka JW, Gurwood AS, Kabat AG, editors. The Handbook of Ocular Disease Management. $11^{\text {th }}$ ed: Review of Ophthometry; 2009. pp. 6-7.

13. Nerad JA. Eyelid and orbital trauma. In: Gabeddy R, Nash S, editors. Techniques in Ophthalmic Plastic Surgery: A Personal Tutorial. Philadelphia: Saunders Elsevier; 2010. pp. 371-389.

14. Leatherbarrow B. Eyebrow ptosis. In: Dunitz M, editor. Oculoplastic Surgery: Taylor \& Francis; 2002. pp. 293297.

15. American Academy of Ophthalmology Staff. The patient with decreased vision: classification and management. In: American Academy of Ophthalmology Staff, editor. Neuroophthalmology. San Francisco: American Academy of Ophthalmology; 2007-2008. pp. 156-157.

16. Wang MY, Spoor TC. Traumatic optic neuropathies. In: Yanoff M, Duker JS, editors. Ophthalmology. New York: Elsevier; 2013. pp. 898-899.

17. Levin L. Traumatic optic neuropathy. Annual Meeting Syllabus North American Neuroophthalmology Society. 2009:75-78.

18. Steinsapir KD, Goldberg RA. Traumatic optic neuropathies. In: Miller NR, Newman NJ, Biousse $\mathrm{V}$, et al. (editors). Clinical Neuroophthalmology: The Essentials. Philadelpia: Lippicott William \& Wilkins; 2008. pp. 431-434.

19. Steinsapir KD, Goldberg RA. Perpective traumatic optic neuropathy: an evolving understanding. Am J Ophthalmol. 2011;151:928-933.

20. Yu-Wai-Man P, Griffiths PG. Steroids for traumatic optic neuropathy. Cochrane Database of Systematic Reviews. 2013;6:CD006032. 